\title{
Nursing Role in Application off Nutritional Guidelines During Hyperemesis Gravid Arum and Its Effect On Patients Outcomes
}

\author{
Manal M. Hassan ${ }^{1}$, Manal F. Mostafa ${ }^{2}$ \& Howieda A. Fouly ${ }^{3}$. \\ 1. Nursing Specialist at Police Hospital in Asyut city, Egypt. \\ 2. Professor of Obstetrics \&Gynecological Nursing, Faculty of Nursing, Assiut University, Egypt. \\ 3. Lecturer of Obstetrics \& Gynecological Nursing, Faculty of Nursing, Assiut University, Egypt.
}

\begin{abstract}
Background: Hyperemesis gravidarum is a complication of pregnancy that affects various aspect of the woman's health, including electrolytes and kidney function, and may have adverse fetal consequences. Recent researches now provide additional guidelines for protection and relief from hyperemesis gravidarum. Alterations to maternal diet and lifestyle can have protective effects. The aim of the study was to assess the effect of nutritional guidelines on pregnant women health statues outcome .Research design: Quasi experimental (pre \& post) test in this study Setting: This study was conducted in obstetric and gynecological departments, antenatal units at police Hospital in Asyut city. Sample: convenience sample consisted of (30) pregnant women, Tools: two tools was used (1) a structured interview questionnaire. (2) Guidelines brochure. Results: highly statically significant difference between pregnant women condition in first and second week in their number of meals per day ( $\mathrm{p} V=0.001$ ). Gain weight ( $\mathrm{p} V=0.001$ ) Number of vomiting per day ( $\mathrm{V}=0.120)$. Conclusion and Recommendations: We conclude that nutritional guidelines during $(\mathrm{HG})$ can be used as an alternative means in addition to standard, antiemetic therapy the study recommends focused on establishing plans for periodical and scheduled training course and educational program for nurses to help improving their knowledge.
\end{abstract}

\section{Key word: Nursing, Nutritional Guidelines \& Hyperemesis Gravidarum.}

\section{Introduction}

Hyperemesis gravidarum (HG) is a severe form of nausea and vomiting which occurs in $0.3 \%$ to $1.5 \%$ of pregnancies (Australian Health Ministers', 2012) Hyperemesis gravidarum is a serious complication of pregnancy in the first trimester. Excessive vomiting of both solid food and liquids may lead to dehydration, ketosis, electrolyte imbalance, thyrotoxicosis and rarely vitamin deficiency in pregnancy. If untreated, it can lead to abortion, intrauterine growth restriction, low-birth-weight infants, and possibly neonatal abnormalities .The effects on the mother include weight loss, fluid and electrolyte disturbances, dehydration, starvation ,Wernicke's encephalopathy, esophageal fistulas, and in rare cases ,death. Severe hyperemesis requiring hospital admission occurs in $0.3-20 \%$ of pregnancies (Australian Health Ministers', 2012) (Boelig, et al., 2013).

Symptoms Often get better after the 20th week of pregnancy but may last the entire pregnancy (Pregnancy" .Office on Women's Health, 2010). The exact cause of hyperemesis gravidarum is not known (Jueckstock, et al., 2010). Risk factors include the first pregnancy, obesity, prior or family history of hyperemesis gravidarum, trophoblastic disorders, and history of eating disorders (Ferri \& Fred, 2012). Maternal complications if (HG) is inadequately treated, hyponatremia, anemia, Wernicke's encephalopathy, kidney failure, central pontione myelinolysis, coagulopathy, atrophy, Mallory -Weiss tears, hypoglycemia, jaundice, malnutrition, Pulmonary embolism, splenic avulsion, or vasospasms of cerebral arteries, deconditioning and deep vein thrombosis.

Midwifery care concerned of urinalysis on every specimen, accurate fluid balance for inpatient, weigh woman on each admission or weekly if she remains an inpatient. Staff should not smell of smoke or use perfume; women should have easy access to a supply of clean vomit bowls, and used vomit bowls should be cleared away promptly. Vomiting, in severe nausea and vomiting during pregnancy (NVP) it is preferable to stop ginger, sea bands shouldn't be used it all because of its ineffectiveness in that case. Encourage rest, give written information/ support groups (Pregnancy Sickness Support).

Nurses advise women to seek early treatment for constipation caused by dehydration. Malnutrition, immobility or medication (Ondansetron), reassure that any stress incontinence is not permanent. Encourage pelvic floor exercises, emotional and psychological support. Ensure that the woman feels that she is listened to and her symptoms believed. In extreme cases refer woman to the Perinatal Mental Health Team if appropriate (Dean\& Shortman, 2014) (Nelson-Piercy, et al., 2011) (NICE, 2013). 


\section{Significance of the study}

Very few studies on nutritional deficiencies as causal factors for hyperemesis gravidarum have been cited in the literature. The research related to nutrition that has been published has focused on suggestion elements, notably zinc and copper. However, an association between hyperemesis gravidarum and deficiency states of these elements has not been found They reported statistically significant lower meat intake and a lower energy percent provided by protein in the nausea and vomiting of pregnancy (NVP) group as well as higher energy percent provided by carbohydrates compered to healthy pregnant women there was also a tendency towards a lower intake of vegetables in the( NVP) group. Also, meat is god source of vitamin B12 and Magnesium. These components were also statistically significant reduced (NVP) group compared to the control group of healthy pregnant women (Latva-Pukkila, et al., 2010).

\section{Aim of the study}

To assess the effect of nutritional guidelines on pregnant women health statues outcome .

\section{Research hypotheses:}

H1: There is a significant relation between nutrition guidelines during hyperemesis gravidarum and feto/maternal outcomes of the disease.

H0: (null hypothesis): There is no significant relation between nutrition during hyperemesis gravidarum and fate/outcomes of the disease.

\section{Patients \& Methods}

\section{Research design}

Quasi experimental (pre \& post) test design was used in this study.

\section{I-Technical design}

\section{Setting}

This study was conducted in obstetrics and gynecological ,outpatient clinic and antenatal units at the police hospital in Assiut city this hospital introduced free services for all specialties, for all families belongs to police profession. The department of study included 8 rooms which contains 16 beds. It receives all cases related to obstetrics \& gynecology.

\section{Sample}

Convenience sample consisted of (30) pregnant women diagnosed with hyperemesis gravidrum in the period from three months started from January / 2017 , to march/2017 duration to collect patients' data. Inclusion criteria

-All pregnant women diagnosed (hyperemesis gravidarum).with the gestational age of 7 To 20 weeks.
-Pregnant women between 19 and 40 years and willingness to participate in the study.

\section{Exclusion criteria}

- All pregnant women diagnosed with hyperemesis gravidarum but refused to participate in the study.

\section{Tools}

A Structured Interviewing sheet was designed by the investigator to be filled from each pregnant woman with Hyperemesis gravidarum who was admitted to the Antenatal Inpatient unit and outpatient clinic.

\section{The data was included the following}

Part 1: Socio-demographic characteristics

(Name, age, address, educational level, residence and occupation).

Part 2: Obstetric history

(Number of Gravidity, Parity, abortions, and number of living children's history of twines)

-Outcomes of previous deliveries if present:

(Number of normal vaginal deliveries, abnormal vaginal deliveries, and Cesarean Sections) .

\section{Part 3: Current antenatal history}

(Gestational age/weeks, previous hyperemesis gravidarum, morning sickness, Preexisting eating, gastrointestinal diseases and other diarrhea ).

\section{Part4: Examination}

(Weight at admission, previous weight before pregnancy, done all investigation or not, number of vomiting per day before admission and after receive medication divided on three levels (mild $(<7)$ moderate (7-12) - severe (>13), and ketone level on admission).

\section{Part5: Nursing Actions for Care Plan}

- Reduce nausea and vomiting (through using brochure)

- Ensure medication is provided on time to control blood levels, of anti-emetics,

- Reduce sensory stimulation by providing a side room away from 'smelly areas', if possible

- Ensuring staff are quiet and free from perfume whilst providing care

- Provide snacks when required where possible.

- Review effectiveness of medication and interventions daily, Prevent further weight Loss, encourage oral food intake where possible,

- Ensure medication regime is controlling vomiting and nutrient loss,

- Provide a snack as and when feels able to eat.

- Provide emotional and Psychosocial Support to, provide a side room where possible to reduce sensory stimulation such as smell and sound and reduce distress from public.

- Ensure family members free from perfumes or cigarette smoke. 


\section{Part6: Nursing followed up of patients after discharge}

The investigator follow-up the patient as following; Phone call to follow up after the first awake and the second week from discharge from the hospital and asking her about the following items . (E.g. Number of meals per day, number of vomiting per day, weight increase or not (weight two per wake),

\section{Procedure (Field Work)}

\section{Phase (1): preparatory phase}

It was concerned with construction and preparation of data collection tools. Managerial arrangement to carry out the study, where the investigator prepared formal requests to the directors of the study settings .The purpose and the nature of the study were explained to gain their acceptance and support. For the pregnant women collocation data this stage took about three months started from January / 2017, and the end of march/2017 duration.

The data collected from available admitted pregnant women. All ethical considerations were clarified to each woman before explaining the nature of the study.

- The investigator asked the women about their socio-demographic data, the obstetric history and the current antenatal outcomes of previous deliveries if present, current antenatal.

- And the investigator nursing followed up of patients after discharge date and the investigations done for those patients and its results by using the patient's hospital record. -Each pregnant woman was interviewed individually by the investigator at the antenatal ward.

- The number interviewed per week was ranged from (2-3) patients. The average time taken for filling each questionnaire was around (10- 15) minutes depending on the response of the patients.

- After the questionnaire filled, in the same session, the patients were provided with knowledge about diet for hyperemesis gravidarum through prepared brochure by investigator.

- This brochure was developed by the investigator and revised by supervisors of the thesis study.

- After the patient discharge of the hospital or outpatient patient is call the first week and the second week to follow up on the general condition and the number of vomiting.

- Each woman was reassured that information obtained would be confidential

- The data were collected over three months, started from January / 2017, and the end of march/2017.

\section{Ethical considerations}

- There was no risk for women during application of the research.
- The study was followed common ethical principles in clinical research.

- Oral consent was obtained from woman who participated in the study. Confidentiality of woman was certainly assured.

- Participants had study subjects have the right to refuse to participate and/or withdraw from the study without any rational any time.

- Study subject privacy was considered during collection of data.

Pilot study

According to pilot the study researcher tested the study questionnaire on $10 \%$ (3) patients then, the purpose of the pilot study was to detect any particular problem in the statements clarity, feasibility, and applicability of the questionnaires necessary changes were done in the assessment and modifications were done on both questionnaires so, the pregnant women selected for the pilot study were excluded in the main study.

\section{Statistical analysis}

The data were tested for normality using the Anderson-Darling test and for homogeneity variances prior to further statistical analysis.

Categorical variables were described by number and percent $(\mathrm{N}, \%)$, where continuous variables described by mean and standard deviation (Mean, SD). Chisquare test and fisher exact test used to compare between categorical variables where compare between continuous variables by t-test.

A two-tailed $p<0.05$ was considered statistically significant.

- Probability (P. value) less than 0.05 were considered significant and less than 0.001 was considered highly significant. 


\section{Results}

Table (1): Distribution of pregnant women with hyperemesis gravidarum according to Socio-demographic characteristics.

\begin{tabular}{|l|c|c|}
\hline \multicolumn{1}{|c|}{ Item } & $\begin{array}{c}\text { Frequency } \\
\text { (N=30) }\end{array}$ & Percentage \% \\
\hline Age & \multicolumn{2}{c|}{$19-37$} \\
\hline Range/ years & \multicolumn{2}{c|}{$26.57 \pm 5.64$} \\
\hline Mean \pm SD/ years & \multicolumn{2}{c|}{} \\
\hline Residence address & 27 & $90.0 \%$ \\
\hline Rural & 3 & $10.0 \%$ \\
\hline Urban & & $23.3 \%$ \\
\hline Educational level & 7 & $20.0 \%$ \\
\hline Illiterate & 6 & $3.3 \%$ \\
\hline read and write & 1 & $26.7 \%$ \\
\hline basic education & 8 & $26.7 \%$ \\
\hline Secondary & 8 & \\
\hline University & & $56.7 \%$ \\
\hline Occupation & 17 & $43.3 \%$ \\
\hline Housewives & 13 & \\
\hline Employer & \multicolumn{2}{c|}{} \\
\hline
\end{tabular}

Table (2): Distribution of pregnant women with hyperemesis gravidarum according to their current antenatal history.

\begin{tabular}{|l|c|c|}
\hline \multicolumn{1}{|c|}{ Current antenatal history } & $\begin{array}{c}\text { Frequency } \\
\text { (No) }\end{array}$ & $\begin{array}{c}\text { Percentage } \\
\text { \% }\end{array}$ \\
\hline Gestational age/weeks & \multicolumn{2}{c|}{$7-20$} \\
\hline Range & \multicolumn{2}{c|}{$10.2 \pm 3.54$} \\
\hline Mean+ SD & 10 & $33.3 \%$ \\
\hline Previous hyperemesis gravidarum & 20 & $67.7 \%$ \\
\hline Yes & & \\
\hline No & 18 & $60.0 \%$ \\
\hline Morning sickness & 12 & $40.0 \%$ \\
\hline Yes & & \\
\hline No & 17 & $56.7 \%$ \\
\hline Preexisting eating & 13 & $43.3 \%$ \\
\hline Yes & & \\
\hline No & 4 & $13.3 \%$ \\
\hline Gastrointestinal diseases & 26 & $86.7 \%$ \\
\hline Yes & & \\
\hline No & 8 & $26.7 \%$ \\
\hline OTHER (diarrhea) & 22 & $73.3 \%$ \\
\hline Yes & \multicolumn{2}{|c|}{} \\
\hline No & & \\
\hline
\end{tabular}


Table (3): Comparison between pregnant women with hyperemesis gravidarum according to their nursing followed up (by phone) after discharge first and second week.

\begin{tabular}{|c|c|c|c|c|c|}
\hline \multirow{2}{*}{ Items } & \multicolumn{2}{|c|}{ first week } & \multicolumn{2}{|c|}{ second week } & \multirow{2}{*}{ P. value } \\
\hline & No & $\%$ & No & $\%$ & \\
\hline \multicolumn{6}{|l|}{ Number of vomiting per day } \\
\hline Mild & 26 & 86.7 & 30 & 100 & \multirow{3}{*}{0.120} \\
\hline Moderate & 4 & 13.3 & 0 & 0 & \\
\hline Severe & 0 & 0 & 0 & 0 & \\
\hline \multicolumn{6}{|l|}{ Number of meals per day } \\
\hline 2-3 Meals & 19 & 63.3 & $\mathbf{0}$ & $\mathbf{0}$ & \multirow{3}{*}{$0.001 * *$} \\
\hline 4-5 Meals & 7 & 23.3 & 14 & 46.7 & \\
\hline$>5$ Meals & 4 & 13.4 & 16 & 53.3 & \\
\hline Mean \pm SD & \multicolumn{2}{|c|}{$3.53 \pm 1.50$} & \multicolumn{2}{|c|}{$5.77 \pm 1.04$} & $0.001 * *$ \\
\hline \multicolumn{6}{|l|}{$\begin{array}{l}\text { Weight increase or not (weight two per } \\
\text { week) }\end{array}$} \\
\hline Yes & 2 & 6.7 & 24 & 80.0 & \multirow{2}{*}{$0.001 * *$} \\
\hline No & 28 & 93.3 & 6 & 20.0 & \\
\hline No & 28 & 93.3 & 0 & 0 & \\
\hline
\end{tabular}

Table (1): Show socio-demographic characteristics for participations. Regarding woman age, the mean of ages was $26.57 \pm 5.64$, for educational level is Illiterate $(23.3 \%)$. Secondary and university educated (26.7\% and $26.7 \%$ ) respectively. For occupation, more than fifty percentages $(56.7 \%)$ are house wives. The vast majority of participations are from rural areas $(90.0 \%)$.

Table (2): Shows the mean of gestational age is $(10.20 \pm 3.54)$ week. As regards the current antenatal condition previous hyperemesis gravidarum $(33.3 \%)$, and More than half of the morning sickness ( 60.0 $\%)$. More than half $(56.7 \%)$ of pregnant women had preexisting eating disorder .as diarrhea $(26.6 \%)$ and gastrointestinal diseases $(13.3 \%)$.

Table (3): Shows there is a statically significant difference between patient's condition in first and second week in their number of meals per day at $(\mathrm{p}=$ $0.001)$. There is astatically significant difference in participation gain weight at $(\mathrm{p}=0.001)$.

\section{Discussion}

Many women are affected by nausea (Australian Health Ministers' 2012) and vomiting (52\%) in the first trimester of pregnancy .Severe vomiting requiring hospitalization occurs in $0.3-20 \%$ of all pregnant women, however hospital admission rates fall from 8 weeks 2 .The peak severity for hyperemesis is around12weeks, and whilst most will resolve by 20 weeks,(Boelig RC, et al., 2013), 10\% will continue throughout pregnancy.

The aim of the study was to assess the effect of nutritional guidelines on pregnant women health statues outcome. The present study included (30) women and it was found that the mean age of women between 19-37 years, with the mean \pm SD of age $(26.57 \pm 5.64)$. This result goes in line with finding of (Suzan, et al., (2015) In a study including (120) women who studied the effect of nurses using for P6 acupressure on nausea, vomiting and retching in women with hyperemesis gravidarum who found that mean age of pregnant women was(26.67 \pm 5.42$)$ at maternity high risk care unit in Mansoura University hospital, Egypt. And this nearly quite similar to study conducted by (Samy saad, et al., (2016) who studied the relationship between helicobacter pylori infection and hyperemesis gravidarum they found that the mean age of pregnant women with department of obstetrics and gynecology, high risk pregnancy unit, Benha University hospital was (25.4- 4.47) .This result similar to study conducted by (Cemil, et al., (2012) who studied about Increased Cys-C Levels in Hyperemesis Gravidarum at the obstetrical outpatient population of a research hospital in Ankara, Turkey, and found that mean age was $(25.4 \pm 5.2)$.

Regarding residence, majority of participants were from rural area, this result is in agreement with (Mahmoud, (2012) who studied the risk factors and prevalence of hyperemesis graviderum among pregnant women at the Woman's health center, Assiut University, Egypt. And found that highest percentages of pregnancy women were living in rural areas. This result somewhat different with study finding of (Suzan, et al., (2015) who found that the majority of women were from urban area .This may be related to different area as in Asyut the most of patients were from rural areas.

According to occupation, more than fifty percentages were housewife (Suzan, et al., (2015) was consistent

Vol , (7) No , (17) June, 2019 
with the results of the current study; they found that more than fifty percentages of their sample women were housewives .However, these finding were disagreement with (Mahmoud, (2012) who confirmed that the highest percentage of women were house-wives.This may be related to the sample size. As regards the current antenatal history of the study, our study, recorded that the majority of women were admitted at the first trimester which was consistent with (Saad, et al., (2016) who reported the same results $(10.2 \pm 3.54)$. The mean of gestational weeks at this study is $(10.2 \pm 3.54)$ weeks. This is also consistent with (Cemil, et al., (2012) .Which reflected that the mean age of gestational weeks are $(9.7 \pm 2.2)$ weeks. This result is in disagreement with (Suzan, et al., (2015) who reported the mean age of gestational weeks is $(12.32 \pm 1.25)$ weeks. May be related to different and nature of the study as gestational age of 10 To 16 weeks.

In our study, third of participants had history of hyperemesis in previous pregnancy. Similarly, in a study done by (Stokke, et al., (2015) who studied Hyperemesis gravidarum, nutritional treatment by nasogastric tube feeding, at Haukeland University Hospital, Bergen, Norway, he reported that one third of participants had the chance of hyperemesis in second pregnancy .This result somewhat different with study finding of (Birkeland, et al., (2015) who studied ( Pregnancy-Unique Quantification of Emesis and nausea) identifies patients with hyperemesis gravidarum and poor nutritional intake: in Norwegian .Who found that the hyperemesis in previous pregnancy more than the fourth .May be related to nature of place of data collection. And sample size of hyperemesis gravidarum.

The current antenatal history revealed that the previous hyperemesis gravidarum about third, small of gastrointestinal diseases and less than of third the other (diarrhea). This result is in disagreement with. (Mahmoud, (2012) who mentioned that few of participants had history of previous hyperemesis graviderum, and less than of third gastrointestinal diseases, respectively .This result somewhat different with the study finding of. (Fell, et al., (2006) who studied the risk factors for hyperemesis gravidarum requiring hospital admission during pregnancy. who mentioned that previous hyperemesis gravidarum less than third, and few of gastrointestinal disorders.

Also the present study shows that the lower mean score between the number of meals per day during first week and second week after discharge $(3.53 \pm 1.50)(5.77 \pm 1.04)$ respectively. This finding was similar to the study of (Stokke, et al., (2015) who found that enteral nutrition after discharge (days) maiden (5.0) (3.0\%-8.0\%).
According to weight increase or not on first week vast majority of the women answered with (No) and second week the majority of the women answered with (yes). This result go in line with finding of (Stokke, et al., (2015) who found that weight gain when discharge by enteral nutrition $(<7 \mathrm{~kg})$ less than third, about ( $\geq 7 \mathrm{~kg}$ ) to discharge by enteral nutrition more than three quarter; Weight gain in pregnancy $(<7 \mathrm{~kg})$ by treatment fluid intravenously about third, $(\geq 7 \mathrm{~kg}$ ) by treatment fluid intravenously three quarter .Treatment peripheral nutrition $(<7 \mathrm{~kg})$ more than third and $(\geq 7 \mathrm{~kg})$ more than half.

\section{Conclusion}

The study it was concluded that nutritional guidelines during hyperemesis gravidarum can be used as an alternative means in addition to standard, antiemetic therapy, as well as it was an effective in reducing nausea and vomiting episodes in women with hyperemesis gravidarum.

\section{Recommendations}

Based on the results of this study it was recommended that:

- Encourage maternity health care settings to apply nutritional guidelines during hyperemesis gravidarum to improve patients' outcomes.

- In general, more attention toward nursing educational curriculum for updating nursing knowledge regarding hyperemesis gravidarum

- Mass media should increase women awareness regarding hyperemesis gravidarum and its effect on pregnancy outcomes.

\section{References}

1. Australian Health Ministers' Advisory Council, (2012): Clinical practice guidelines: Antenatal care- Module 1.Canberra: Australian Government Department of Health and Ageing; Available from:http://www.health.gov.au/antenatal.

2. Boelig R., Barton S., Saccone G., Kelly A., Edwards S., Berghella V., (2013): Interventions for treating hyperemesis gravidarum, Cochrane Database Syst Rev. 2016, 5, CD010607.

3. Birkeland E., Stokke G., Tangvik R., Torkildsen E., Boateng J., Wollen A., Albrechtsen S., Flaatten H., Trovik J., (2015): identifies patients with hyperemesis gravidarum and poor nutritional intake .Norwegian PUQE (Pregnancy-Unique Quantification of Emesis and nausea): a prospective cohort validation study. PLoS One; 10(4):e0119962.

4. Cemil B., Suleyman A., Nermin A., Feyzi G., (2012): Increased Cys-C Levels in Hyperemesis

Vol , (7) No , (17) June, 2019 
GravidarumJ Clin Gynecol Obstet • 2012;1 (1): 10-14Original ArticleCemil Bilir, Sultan Orhan mh 1145 sk no: 14

5. Dean C., Shortman Amanda, (2014): Hyperemesis Gravidarum: The Definitive Guide.

6. Fejzo M, Poursharif B, Korst L, Munch S, MacGibbon K, Romero R, (2009): Symptoms and pregnancy outcomes associated with extreme weight loss among women with hyperem esis gravidarum . J Womens Health (Larchmt); 18:1981-7.

7. Ferri's , Fred F., (2012): hyperemesis gravidarum, Ferri's clinical advisor 20135 books in $1(1 \mathrm{st} \quad$ ed.). Elsevier Mosby. p. 538.ISBN 9780323083737.

8. Fell D., Doddsl., Joseph K., Allenv V., (2006): and BUTLER B.: Risk factors for hyperemesis gravidarum requiring hospital admission during pregnancy. Obstetrics and Gynecology, 107 (2): 277-284, 2006. [PubMed:16449112] Part 1.

9. Jueckstock, J., Kaestner, R., Mylonas, I., (2010): "Managing hyperemesis gravidarum: a multimodal challenge.". BMC medicine 8: 46. doi:10.1186/ 1741-7015-8-46. PMC: 2913953. PMID 20633258.

10. Latva-Pukkila U., Isolauri E., Laitinen K., (2010): Dietary and clinical impacts of Nausea and vomiting in pregnancy .Journal of human nutrition and dietetics: the official Journal of the British Dietetic Association. Feb; 23 (1):6977.pub Med PMID: 19943842.

11. Mahmoud, G., (March, 2012): Prevalence and Risk Factors of Hyperemesis Graviderum among Egyptian Pregnant Woman at the Woman's Health Center .Med. J. Cairo Univ., Vol. 80, No. 2, 161 1686.

12. Nelson-Piercy C., (2011): Management of nausea and vomiting in pregnancy: British Medical Journal Vol 342 pp1-8

13. NICE, (2013): http:/cks.nice.org.uk/nausea vomiting-in-pregnancy .

14. Pregnancy". Office on Women's Health, (September 27, 2010): Retrieved 5 December 2015.

15.Samy Saad, Mohammed ElSherbini, Tamer Assar, Riham ElSawy. (2016): Evaluation of the Relationship between Helicobacter Pylori Infection and Hyperemesis Gravidarum International Journal of Advanced Research, Volume 4, Issue 1, 1137- 1142 http://www.journalijar.com

16. Stokke G., Gjelsvik B., Flaatten K., (2015); Hyperemesis gravidarum, nutritional treatment by nasogastric tube feeding: a 10-year retrospective cohort study. Acta Obstet Gynecol Scand 2015; 94:359.
17.Suzan E., Mansour, Emam M., Elghory A., Sheb. A., (2015): Effect of Nurses Using for P6 Acupressure on Nausea, Vomiting and Retching in Women with Hyperemesis Gravidarum. IOSR Journal of Nursing and Health Science (IOSRJNHS) e-ISSN: 2320-1959.p-ISSN: 2320-1940 Volume 4, Issue 4 Ver. II (Jul. -Aug. 2015), PP 01-09 